\title{
EFFECT OF PVP AND POLYBOND COMPATIBILIZERS ON DYNAMIC PROPERTIES OF POLYMER BLENDS ANALYZED WITH DMTA
}

\author{
Adam Gnatowski ${ }^{1}$, Marcin Sosnowski \\ 1 Czestochowa University of Technology, Faculty of Mechanical Engineering and Computer Science, \\ 21 Armii Krajowej Av, 42-200 Czestochowa, Poland, gnatowski@ipp.pcz.pl \\ 2 Jan Dlugosz University in Czestochowa, Faculty of Mathematics and Natural Sciences, 13/15 Armii Krajowej \\ Av, 42-200 Czestochowa, Poland, m.sosnowski@ajd.czest.pl
}

Received: 2017.07.09

Accepted: 2018.02.01

Published: 2018.03.01

\begin{abstract}
The properties of the polymer blends depend significantly on the type of the components. That kind of influence is manifested especially in the change of physical properties. The crucial condition for reaching the homogeneity and the properties of a polymer material is its mutual miscibility. Additional agents that make mixing easier are usually applied. They have reactive effect which results in a chemical modification of output polymer along with the change in its chemical structure and the structure of macrochains. In order to achieve this within the confines of the carried research, the polyvinylpyrrolidone (PVP) and polybond has been used. Some results concerning mechanical properties of polypropylene (PP) and polyamide (PA) blends with the addition of PVP and polybond are presented in the paper. In case of mixing PP with PVP, the hydrophobic interactions occur in the created macromolecules with the participation of the hydrocarbon chains. In case of mixing PA with PVP, the PVP solution in PA is created, with strong intermolecular interactions, including the hydrogen ones. The intermolecular interactions occur and they differently influence parameters of the modified materials in the blends on the basis of such polymers. Therefore the aim of the research was to evaluate the influence of the compatibilizers such as PVP and Polybond 3150 on the dynamic properties of PP/PA blends. The analysis of dynamic proprieties of polymer blends was performed with the Dynamic Mechanical Thermal Analysis (DMTA). The mixing of polymers in different proportions with compatibilizers (PVP, Polybond 3150) results in materials of completely different properties in comparison to the base materials. Detailed results concerning response to sinusoidal load in function of temperature and frequency are presented in the paper.
\end{abstract}

Keywords: polymers, mechanical properties, blends, polybond, polyvinylpyrrolidone

\section{INTRODUCTION}

The processes of mixing polymers with compatibilizers are used in order to produce polymeric materials of specific mechanical properties. This is justified by the number of advantages of manufacturing methods, expanded possibilities of their application and operating conditions. Properties of products manufactured from polymer blends depend on the nature of the compatibilizer and polymer structural factors such as the molecular weight, chemical structure of macromolecules, the physical construction of the chain, crystallinity and molecular orientation in different conditions (temperature, time of load, pressure, strain, etc.) [1-4]. The blends obtained up till now are characterized by improved mechanical as well as thermal and electrical properties [5-14].

Research of dynamic proprieties of polymer materials performed with the Dynamic Mechani- 
cal Thermal Analysis (DMTA) are one of means of estimating the transformations in materials over a wide range of temperatures and frequencies of load variations. The DMTA is based on exposing the sample to sinusoidal forced vibrations of the frequency ranging from $1 \mathrm{~Hz}$ to $1000 \mathrm{~Hz}$.

The variation of storage modulus and angle of mechanical losses are obtained within the carried out research. The above mentioned factors allow to estimate the correlation of the molecular construction and mechanical proprieties of polymer materials [1-6].

\section{MATERIALS, APPARATUS AND METHODS}

The following materials were used for the study:

- Polypropylene - Malen P, J - 400 manufactured by Petrochemia Plock S.A.

- The propylene homopolymer obtained in the process of suspension polymerization. Malen $\mathrm{P}, \mathrm{J}-400$ is characterized by satisfactory mechanical properties and good processing in the conditions of the injection molding [7-10, 15].

- Polyamide 6 - Tarnamid T 27 manufactured by Grupa Azoty Tarnow S.A.

- It is a kind of polyamide characterized by medium molecular weight. It is used in the injection molding of products of high strength requirements, including thin-walled products applied in monofilaments, lines, bristles and fibres production [1-3, 10-12].

- Polyvinylpyrrolidone (PVP) [3, 16] of small molecular weight $(12 \pm 2 \mathrm{k})$

- The colourless, amorphous, hygroscopic polymer. Polyvinylpyrrolidone forms complexes with many inorganic and organic compounds particularly with dyes, vitamins and medicines. It mixes also with numerous resins, polymers and plasticisers $[16,17]$.

- Polybond 3150

- The thermoplastic anhydrite maleic used as the chemical factor uniting and compatibilizing to the modification of the homopolymer of the polypropylene. This product can be used in all traditional and modern processes of polymers manufacturing [18]. It influences the processing properties of blends by affecting both resistance to aging and temperature [8-10].

Blends of different percentage level of polyamide 6 and polypropylene with the addition of compatibilizers were prepared within the research. Polymer blends of the following composition were analyzed:

- PP/PAblends with 3\% of polyvinylpyrrolidone:

- 30\% $\mathrm{PP} / 70 \% \mathrm{PA}$

- $50 \% \mathrm{PP} / 50 \% \mathrm{PA}$

- $70 \% \mathrm{PP} / 30 \% \mathrm{PA}$;

- PP/PA blends with $3 \%$ of Polybond 3150 :

- 30\% $\mathrm{PP} / 70 \% \mathrm{PA}$

- $50 \% \mathrm{PP} / 50 \% \mathrm{PA}$

- $70 \% \mathrm{PP} / 30 \% \mathrm{PA}$;

Because of the conditional mixing of polyamide and polypropylene, it was essential to apply the compatibilizers in order to obtain the blend of proper homogeneity and defined properties. The paper presents the research concerning blends with different compatibilizers. The preparation of the PP/PA blend with PVP was began with weighing the components with the use of digital balances Sortorius AG GO TTINGEN and CAS MODEL SW-1. Before processing, blends were dried in the Shini CD Cabinet Dryder chamber at the temperature of $80^{\circ} \mathrm{C}$ for 12 hours. Blends were prepared by the extraction of obtained polymer material in the plastic state using the plastifying set of the KRAUSS MAFFEIKM 65-160 $\mathrm{C} 1$ molding machine. The blend was plasticized in the set for 180 seconds. The PVP was used in the form of powder and Polybond 3150, polyamide 6 (Tarnamin 27) as well as polypropylene (Malen P J-400) were used in the form of granules. Blends with Polybond 3150 compatibilizer were prepared on the stamping-press with static homogenizer. The molding parameters were chosen in accordance with the blend (depending on the proportional composition of the analyzed blend). The base materials are characterized by different processing parameters and therefore the molding process parameters were determined by the percentage level of base material in the blend as depicted in Table 1. In order to obtain the optimal properties of produced materials, the cooling time as well as the temperature of the mold was dependent on polyamide content in blend and the addition of different compatibilizers of defined processing properties and structure. The molding temperature was $250^{\circ} \mathrm{C}$ for blends of $50 \% \mathrm{PP} / 50 \% \mathrm{PA}$ and $30 \% \mathrm{PP} / 70 \% \mathrm{PA}$ and $235^{\circ} \mathrm{C}$ for blends of $70 \% \mathrm{PP} / 30 \% \mathrm{PA}$. The samples were prepared using the injection mold installed on KRAUSS MAFFEI molding machine of the following specification: closing force $650 \mathrm{KN}$, perpetual screw diameter $30 \mathrm{~mm}$. 
Table 1. Molding parameters of the analyzed blends

\begin{tabular}{|c|c|c|c|}
\hline & $\begin{array}{l}30 \% \mathrm{PP} / 70 \% \mathrm{PA} \\
50 \% \mathrm{PP} / 50 \% \mathrm{PA}\end{array}$ & PP70\%/PA30\% & Samples with PVP \\
\hline Temperature of extruder nozzle $\left[{ }^{\circ} \mathrm{C}\right]$ & 265 & 250 & 230 \\
\hline Temperature of zone I $\left[{ }^{\circ} \mathrm{C}\right]$ & 265 & 250 & 250 \\
\hline Temperature of zone II $\left[{ }^{\circ} \mathrm{C}\right]$ & 260 & 245 & 210 \\
\hline Temperature of zone III $\left[{ }^{\circ} \mathrm{C}\right]$ & 255 & 240 & 190 \\
\hline Injection pressure [MPa] & 100 & 100 & 60 \\
\hline Cooling time [s] & 20 & 10 & 20 \\
\hline Holding pressure [MPa] & 350 & 350 & 350 \\
\hline Holding time [s] & 5 & 5 & 15 \\
\hline Temperature of mold $\left[{ }^{\circ} \mathrm{C}\right]$ & 60 & 60 & 40 \\
\hline
\end{tabular}

The research with the use of DMTA was performed on NETZSCH DMA 242 device with the use of three-point bender. The samples were examined at temperature rising with the speed of $2{ }^{\circ} \mathrm{C}$ per minute and two frequencies of the bending equal $1 \mathrm{~Hz}$ and $10 \mathrm{~Hz}$. The measurement started at $20{ }^{\circ} \mathrm{C}$ and finished at approx. $140^{\circ} \mathrm{C}$. The values of storage modulus $\mathrm{E}^{\prime}$ and angle of mechanical losses were calculated with the use of computer program on the basis of measured force and deformation. The sample dimensions $(55 \mathrm{~mm}$ length, $10 \mathrm{~mm}$ width, $4 \mathrm{~mm}$ thickness) were also taken into account.

\section{RESULTS AND DISCUSSION}

The results obtained with DMTA are depicted in Fig. 1 to Fig. 4 in the form of plots of storage modulus $\mathrm{E}^{\prime}$ and angle of mechanical losses versus temperature for frequencies equal $1 \mathrm{~Hz}$ and $10 \mathrm{~Hz}$. The blends are characterized with significant differences of dynamic properties. The storage modulus in all cases (PA and PP unmixed with compatibilizers as well as blends with compatibilizers) are qualitatively comparable but quantitatively different. In case of PP $70 \% / \mathrm{PA} 30 \%$ blend, the storage modulus is almost identical in terms of shape as well as values. Therefore it can be stated that the kind of compatibilizer does not influence the modulus in PP/PA blend of the defined composition nor the compatibilizer causes the properties to be shifted in the direction of materials applied in the different blend of lower content of one of the polymers. The analysis of the variation of the loss angle leads to conclusion that it is strongly dependent on the kind of compatibilizer. In case of PVP blend, the greatest values of loss angle occur at temperature equal almost $95^{\circ} \mathrm{C}$ whereas in case of polybond blend it is ap- prox. $85^{\circ} \mathrm{C}$ for the frequency of $1 \mathrm{~Hz}$. Moreover there is less variation in the course of loss angle in case of PVP blend. It can be stated that it is almost linear up till the temperature of $75^{\circ} \mathrm{C}$. The PP50\%/PA50\% blend is characterized by significant differences in the values of storage modulus.

In case of blend with polybond, the storage modulus reaches approx. $1900 \mathrm{MPa}$ at temperature equal $20^{\circ} \mathrm{C}$ and decreases to $420 \mathrm{MPa}$ at $130^{\circ} \mathrm{C}$ for the frequency equal $10 \mathrm{~Hz}$. It behaves similarly at $1 \mathrm{~Hz}$ but the gained values are lower. The blend with PVP is characterized by storage modulus of $2560 \mathrm{MPa}$ for $10 \mathrm{~Hz}$ and then decreases to approx. $470 \mathrm{MPa}$ at $130^{\circ} \mathrm{C}$. The analysis of mechanical losses angle for blend with PVP reveals that the maximal value for frequency equal $10 \mathrm{~Hz}$ is gained at approx. $52^{\circ} \mathrm{C}$ and in case of blend with polybond it is gained at approx. $85^{\circ} \mathrm{C}$. For frequency equal $1 \mathrm{~Hz}$, the characteristic is qualitatively similar but slightly different in the quantitative aspect. In case of $30 \% \mathrm{PP} / 70 \% \mathrm{PA}$ blend, the significant increase of storage modulus is observed for the polybond at the beginning of the process $\left(20^{\circ} \mathrm{C}\right)$. The maximal value of mechanical losses angle for PVP blend at $10 \mathrm{~Hz}$ is shifted to the range of higher temperatures than it is observed for the blend with polybond.

\section{CONCLUSIONS}

The carried out research using DMTA indicate the possibility of preparing the blend based on polyamide and polypropylene with different compatibilizers as well as indicate the influence of compatibilizers on the dynamic properties of the blends. The mixing of polymers in different proportions with compatibilizers (PVP, Polybond 3150 ) results in materials of completely different properties than the base materials. The me- 

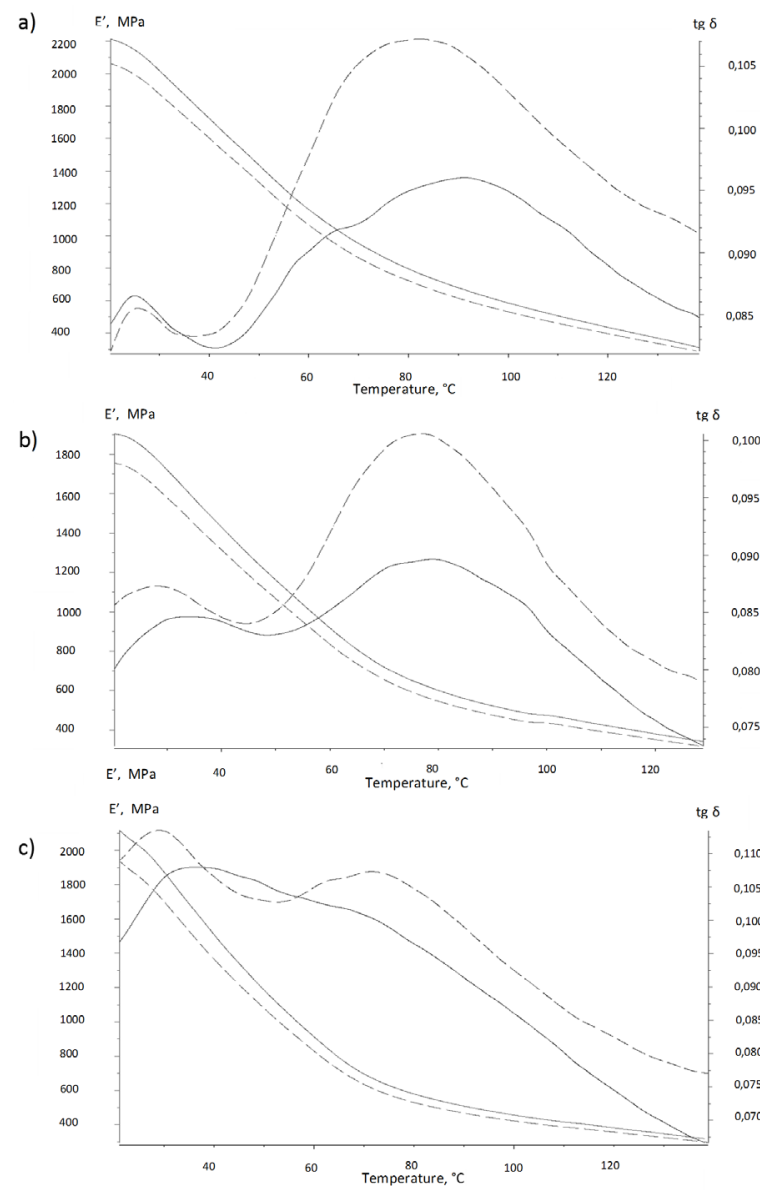

Fig. 1. Storage modulus E' and angle of mechanical losses $\delta$ in function of temperature for blend with 3\% of polybond (dashed lines $-1 \mathrm{~Hz}$, continuous lines - $10 \mathrm{~Hz}$ ): a) $70 \% \mathrm{PP} / 30 \% \mathrm{PA}$, b) $50 \% \mathrm{PP} / 50 \% \mathrm{PA}$, c) $30 \% \mathrm{PP} / 70 \% \mathrm{PA}$
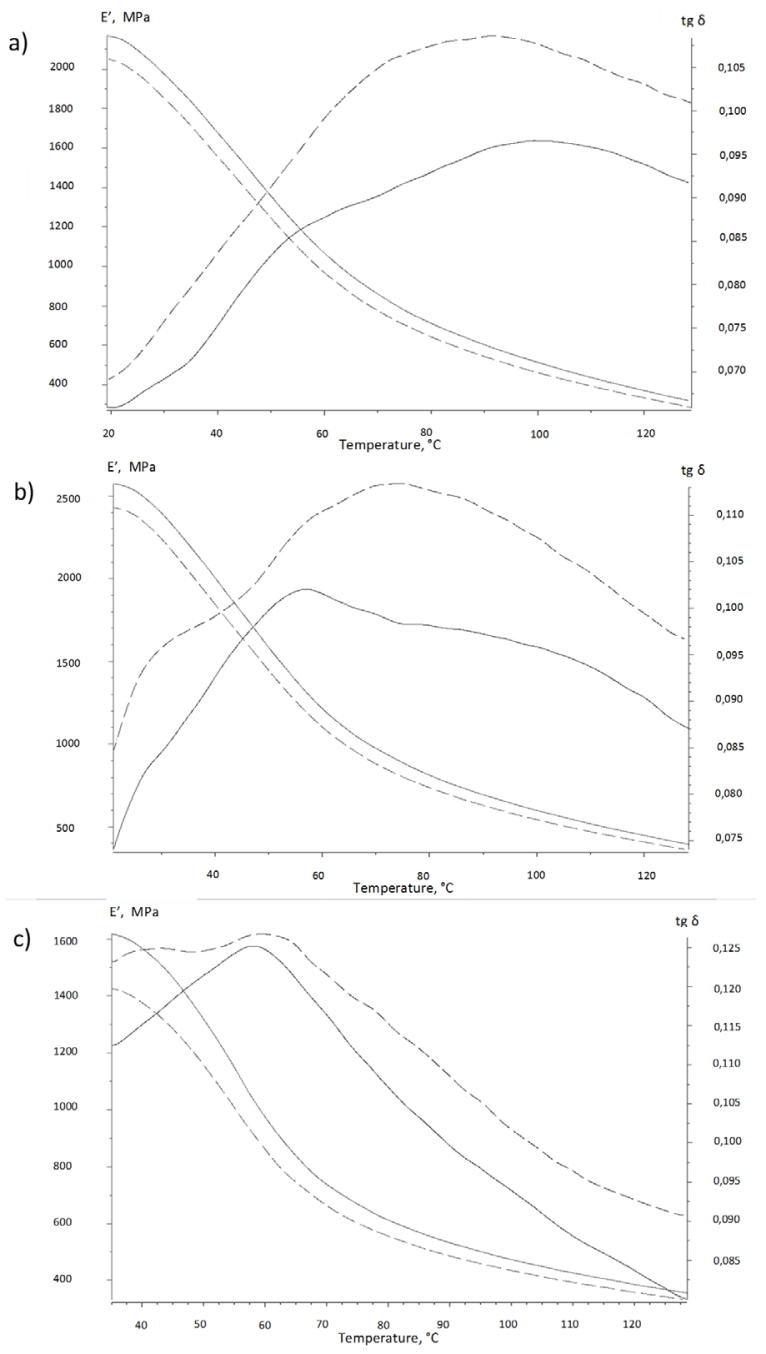

Fig. 2. Storage modulus E' and angle of mechanical losses $\delta$ in function of temperature for blend with $3 \%$ of polyvinylpyrrolidone (dashed lines -1 $\mathrm{Hz}$, continuous lines $-10 \mathrm{~Hz}$ ): a) $70 \% \mathrm{PP} / 30 \% \mathrm{PA}$,

b) $50 \% \mathrm{PP} / 50 \% \mathrm{PA}$, c) $30 \% \mathrm{PP} / 70 \% \mathrm{PA}$

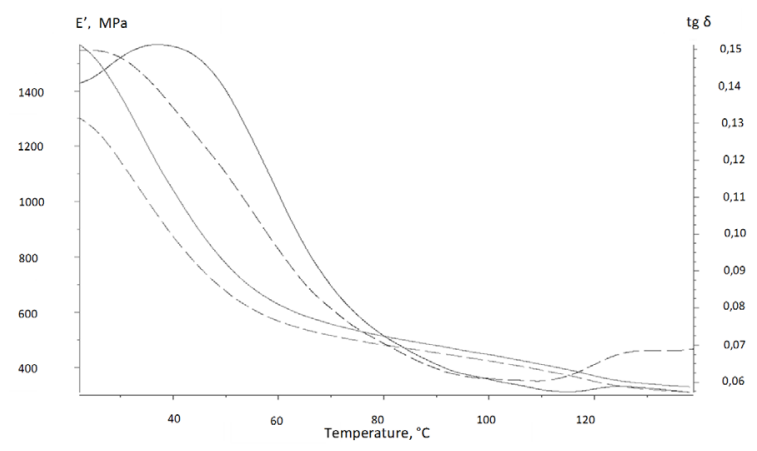

Fig. 3. Storage modulus E' and angle of mechanical losses $\delta$ in function of temperature for PP

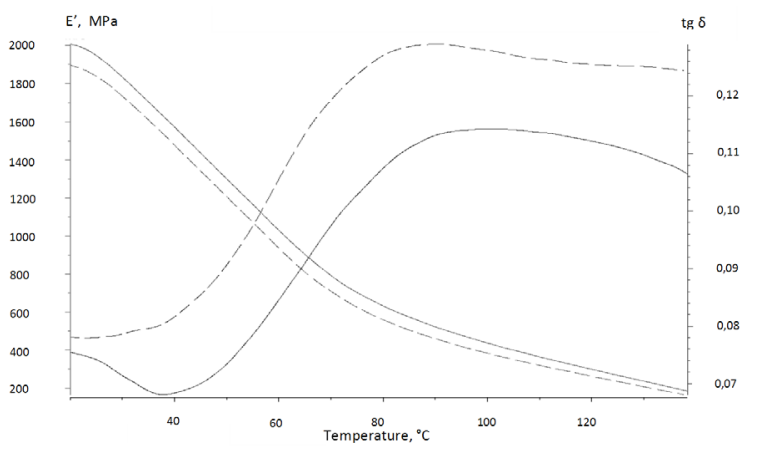

Fig. 4. Storage modulus E' and angle of mechanical losses $\delta$ in function of temperature for PA 
chanical properties of obtained polymers were analyzed with DMTA method. The response of the analyzed sample to sinusoidal load was measured in function of temperature and frequency. The load in DMTA research corresponds to real loads existing in practical applications of polymer materials. The analysis of obtained results allow to estimate the properties of specific polymer material in real conditions and define the damping properties, resistance to time-varied load and thermal resistance.

\section{LITERATURE}

1. Jakubowska P., Sterzyński T., Samujło B., Rheological Studies of Highly-Filled Polyolefin Composites Taking Into Consideration P-V-T Characteristics Polimery 2010, 5, pp. 379.

2. Żuchowska D.: Construction polymers. WNT, Warsaw, 2000.

3. Gnatowski A., Koszkul J., Investigations of the Influence of Compatibilizer and Filler Type on the Properties of Chosen Polymer Blends, Journal Material Processing Technology 2005, Vol. 162-163, 52-58.

4. Gnatowski A., Ziewiec A., Gnatowska R.: Impact analysis performance injection in polymer composites processing shrinkage, AIP Conference Proceedings 1648, 850127, 2015, http://doi. org/10.1063/1.4913182.

5. Koning C., Duin M. V., Paagnoulle Ch., Jerome R., Strategies for compatibilization of polymer blends, Progress in Polymer Science, Vol. 23, 1998, 707-757.

6. Bucknall, C.; Paul, D.R. Polymer Blends, Formulation and Performance; JohnWiley and Sons: New York, NY, USA, 2000.

7. Dharmarajan N., Datta S., Ver Strate G., Ban
L., Compatibilized polymer blends of isotactic polypropylene and styrene-maleic anhydride copolymer. Polymer, Vol. 36, No. 20, 1995, 3849-3861.

8. Manning S.C., Moore R. B., Reactive compatibilization of polypropylene and polyamide- 6.6 with carboxylated and maleated polypropylene, Polymer Engineering and Science Vol. 39, No 10, 1999, 1921-1926.

9. Campoy J., Arribas J. M., Zaporta U. M., Crystallization kinetics of polypropylene-polyamide compatibilized blends, European Polymer Journal, Vol. 31, No 5, 1995, 475-480.

10. Ohlsson B., Hassander H., Törnell B., Effect of the mixing procedure on the morphology and properties of compatibilized polypropylene/polyamide blends, Polymer Engineering and Science, Vol. 39, No 20, 1998, 4715-4721.

11. Robeson, L.M. Polymer Blends, A Comprehensive Review; Carl Hanser: Cincinnati, OH, USA, 2007

12. Isayev, A. Encyclopedia of polymer blends. Fundamentals; Wiley-VCH: Weinheim, Germany, 2011.

13. Papadopoulou, C.P.; Kalfoglou, N.K. Comparison of compatibilizer effectiveness for PET/PP blends:Their mechanical, thermal and morphology characterization. Polymer 2000, 41, 2543-2555.

14. Stary, Z.; Pemsel, T.; Baldrian, J.; Munstedt, H. Influence of a compatibilizer on the morphology development in polymer blends under elongation. Polymer 2012, 53, 1881-1889.

15. Koszkul J., Polymeric materials, Publication of Technical University of Czestochowa, 1999.

16. Sidielkowskaja F.P., Chemistry of N-vinylpyrrolidone and of his polymers. Science-Moscow, 1970.

17. Gnatowski A., Suberlak O., Postawa P., Functional materials based on PA6/PVP blends, Journal of Achievements in Materials and Manufacturing Engineering, Vol. 18, 2006, 91-94.

18. Catalog UNIROYAL CHEMICA LIMITED 3/93. 